\title{
A emergência do discurso da inclusão escolar na biopolítica: uma problematização em busca de um olhar mais radical*
}

\author{
PEDRO ANGELO PAGNI \\ Universidade Estadual Paulista, Marília, SP, Brasil
}

\section{RESUMO}

Os enunciados do discurso sobre a inclusão se formaram em consonância com a configuração atual da biopolítica no neoliberalismo, por vezes desconsiderando as dissonâncias geradas pela experiência, pela diferença que singulariza as relações com a deficiência e pelo acontecimento que a significa na escola. Ao recobrar esses aspectos, o presente artigo procura problematizar a dispersão contida nos discursos sobre a inclusão e indicar outro olhar sobre a relação com a deficiência nos contextos educacionais. Para tanto, recorre-se ao pensamento tardio de Michel Foucault para analisar algumas pistas sobre a emergência e os limites dos discursos sobre a inclusão escolar. Para buscar outro olhar sobre o assunto, enfatiza-se a positividade da deficiência na escola e a necessidade de se passar do discurso sobre a inclusão a práticas em que a relação com os deficientes lance aos atores dessa instituição desafios de uma diferenciação ética e de um posicionamento político comuns.

PALAVRAS-CHAVE

biopolítica; inclusão; deficiência; educação escolar.

* Este ensaio apresenta resultados parciais da pesquisa Biopolitica, ética da diferença e educação: um outro olhar sobre a inclusão escolar - retratos da positividade da deficiência, com financiamento dos editais de Auxílio à Pesquisa da Fundação de Amparo à Pesquisa do Estado de São Paulo (FAPESP) (2014-2015), de ciências humanas e sociais aplicadas (2014-2016) e de Bolsa Produtividade do Conselho Nacional de Desenvolvimento Científico e Tecnológico (CNPq) (2014-2016). 


\title{
THE EMERGENCE OF DISCOURSE ON THE SCHOOL INCLUSION IN BIOPOLITICS: A PROBLEMATIZATION IN SEARCH OF A MORE RADICAL LOOK
}

\begin{abstract}
The discourse on the inclusion statements formed in line with the current setting of biopolitics in neoliberalism, sometimes disregarding the dissonances generated by experience, the difference that highlights relations with disability and by the event that means at school. To recover these aspects, this article aims to discuss the form contained in the discourses about the inclusion and indicate another glimpse into the relationship with disability in educational contexts. To this end, we resorted to the afterthought of Michel Foucault to analyze some clues about the emergence and the limits of the discourses on school inclusion. To get another look at the subject we will focus on the positivity of disabilities in school and the need to move from discourse on the inclusion practices in which the relationship with the disabled lance the actors of this institution challenges of ethics differentiation and political positioning common.
\end{abstract}

KEYWORDS

biopolitics; inclusion; disabilities; school education.

\section{LA EMERGENCIA DEL DISCURSO DE INCLUSIÓN ESCOLAR EN BIOPOLITICA: UNA PROBLEMATIZACIÓN EN BUSCA DE UNA MIRADA MÁS RADICAL}

\section{RESUMEN}

Los enunciados del discurso de la inclusión han sido formados en consonancia con la configuración actual de biopolítica en el neoliberalismo, a veces haciendo caso omiso de las disonancias generadas por la experiencia, la diferencia que destaca relaciones con discapacidad y por el acontecimiento que significa en la escuela. Al recuperar estos aspectos, este ensayo problematiza la dispersión que figura en los discursos sobre la inclusión e indica otra mirada a la relación con la discapacidad en contextos educativos. Para eso, recurrimos a lo pensamiento de Michel Foucault para analizar la aparición y los límites de los discursos sobre la inclusión en la escuela. Proponemos la posibilidad de la positividad de la discapacidad en la escuela y la necesidad de pasar del discurso sobre la inclusión a las prácticas en que la relación con las personas discapacitadas provoca en los actores de esta institución desafíos de diferenciación ética y de posiciones políticas comunes.

PALABRAS CLAVE

biopolítica; inclusión; discapacidades; educación escolar. 
Nos últimos anos, no Brasil, a temática da formação humana constituiu-se no principal eixo de análise dos estudos em filosofia da educação. A justificativa para que esse tema se tornasse objeto desses estudos, como demonstrado por Pagni $(2013,2014 b)$, foi a de que, por um lado, teria se tornado um terreno profícuo para a interlocução dos pesquisadores desse campo e para a sua constituição, seguindo um modo habitual de pesquisa bibliográfica, de natureza teórica, próxima de métodos estruturais ou hermenêuticos, como os empregados pela filosofia; por outro, pelo diagnóstico de que seria capaz de se problematizar uma tendência, observada nas últimas décadas, de restringir a educação escolar às tecnologias de ensino e de aprendizagem que, por mais que tenham seu lugar naquela ação, se sobrepuseram ao seu sentido formativo. Se essa problematização da tendência geral produziu um razoável número de estudos, com o rigor conceitual e a precisão teórica esperados pelo campo da filosofia da educação, por sua vez os resultados dessas conquistas foram pouco reconhecidos pela filosofia e pouco efetivos na interlocução com outros campos da educação no Brasil.

Entre esses estudos sobre o tema da formação, alguns o abordaram pela ótica da estética da existência de Michel Foucault, tal como demonstrou Freitas (2013) e Groppa (2013). Desse ponto de vista, a formação ocorreria como uma arte da existência por meio da qual o sujeito ético transforma-se ao experimentar a si próprio, tornando-se objeto de seu pensar e mobilizando uma atitude para enfrentar os acontecimentos que acolhe e enfrenta. Nesse trabalho de si sobre si, como argumentou Pagni (2014a), a vida é vista não apenas como algo a ser governado pelos dispositivos de subjetivação e pelas tecnologias do biopoder existentes, encarnados pelas práticas e incorporados pelos saberes em circulação em instituições como a escola, como também se apresenta como potência que resta ou que excede a essas formas de seu governamento, resistindo-lhe e criando outros modos de existência.

No âmbito da biopolítica atual, os processos de subjetivação que conseguem catalisar essa potência para interpô-la ao controle excessivo da vida e resistir-lhe em busca de modos de existências mais livres, mesmo em instituições disciplinares e normativas como a escola, constituem um campo privilegiado de uma ética que estrategicamente desempenha um importante sentido político na atualidade. Isso porque o estudo desse campo, antes do que concorrer para o desenvolvimento de dispositivos de subjetivação e de tecnologias do biopoder que estendam a vida ao seu extremo, produzindo formas de exceção e de extermínio - denominadas de fascistas por Foucault (2004) -, pode indicar linhas de fuga capazes justamente de resistir-lhes e de criar modos outros de existência em que se potencialize.

Pode-se dizer que, dessa perspectiva, a administração excessiva da vida abrangeu também os dispositivos de subjetivação e as tecnologias do poder utilizados nas escolas na configuração atual da biopolítica, assim como as condições de possibilidade de os atores dessa instituição desenvolverem práticas de resistência, mobilizados por atitudes múltiplas que compreendem certa diferenciação daquilo que deles se espera e, por vezes, uma diferença que não resulta imediatamente de uma atitude, e sim de um acidente. Essa parece ser a condição de inúmeros atores 
que adentraram mais recentemente a instituição escolar, gerando uma série de questionamentos acerca da eficiência das tecnologias e dos procedimentos adotados e também da própria formação do docente que atua nessa instituição para dar conta dessa diversidade ética emergente, aceitar a diferença que a compreende e, em seu interior, a deficiência como algo produtivo, em um contexto no qual reinou a identidade e uma racionalidade homogeneizadora.

No caso particular da deficiência, a formação é atravessada pelos acidentes que deformam o modo de ser desses sujeitos involuntariamente, movidos, conforme afirma Malabou (2009), por uma plasticidade destrutiva - o problema parece ser ainda mais agudo e a diferença em questão parece ser ainda mais radical. Isso porque uma série de dispositivos foi elaborada a fim de minimizar os efeitos dessa vida anômala, deficiente, que adentra a essa instituição tentando atenuar a diferenciação desses atores, capturá-los e integrá-los por meio dos discursos sobre a inclusão escolar e de práticas denominadas inclusivas.

Por essa razão, interessa a este ensaio problematizar pela ótica do projeto filosófico de Michel Foucault a emergência dos discursos sobre a inclusão na atualidade e, em particular, os dispositivos que os colocam em circulação para legitimar ou para produzir, desde os regulamentos legais que os instauram, algumas práticas ditas inclusivas na instituição escolar. Para tanto, não se procurou atualizar as análises foucaultianas sobre a emergência da biopolítica e do biopoder no tempo presente, nem recorrer a atualizações do diagnóstico elaborado pelo filósofo francês, largamente desenvolvidas de Deleuze a Lazzarato, passando por Hardt e Negri, Agamben, Spósito, Heller, Gross, nos termos indicados por Ugarte Pérez (2006), Rabinow e Rose (2006), Duarte (2010), entre outros. Também não se deteve aqui, embora não se perca de vista esse exercício, a encontrar na vida, no vivente e na estética ou na ontologia que a compreende uma expressão dos restos ou dos excessos que resistem e recriam a própria existência diante da configuração atual da biopolítica.

Embora essa temática específica tenha sido desenvolvida por estudos como os de Skliar (2001), Veiga-Neto e Lopes (2007), Lopes e Rech (2013) e Santos e Klauss (2013), parece que nela se vislumbra apenas a ponta de um iceberg, sobretudo caso se explore o discurso sobre a inclusão em sua dispersão e as diferentes formas de legitimação das práticas ditas inclusivas na escola. Nesse caso, ao contrastar as análises da biopolítica com a ontologia da diferença, para usar uma expressão de Revel (2004), procura-se vislumbrar as resistências expressas em alguns modos de existência, de vidas errantes, deficientes e desviantes aos dispositivos atuais do biopoder, encontrando nessas deficiências uma das possíveis formas de diferenciação ética emergentes na escola e acontecimentos capazes de colocar em xeque os processos de subjetivação dominantes nessa instituição.

Esse é o recorte a que este ensaio se propõe, uma vez que o tema é bastante amplo, com vistas a sugerir um início de discussão para que o assunto, emergente na filosofia da educação, possa ampliar suas margens de interface com campos como os da educação especial, propiciando a constituição de outro olhar sobre a deficiência na escola. 


\section{NORMALIZAÇÃO, PRENÚNCIOS DE INCLUSÃO E EDUCAÇÃO}

Algumas pistas sobre a emergência da inclusão do discurso médico e nas tecnologias do poder podem ser encontradas na obra de Foucault (2010), Os anormais, particularmente na passagem em que o autor aborda a substituição do modelo de segregação e exclusão para o de inclusão dos doentes, dos loucos, no âmbito das cidades europeias, entre o final do século XVII e meados do XVIII.

O filósofo francês caracteriza essa passagem, historicamente falando, no momento em que a "exclusão dos leprosos" foi substituída pela "inclusão do pestífero", em que aqueles acometidos pela peste, em vez da expulsão pelos agentes do poder público, teriam sido fixados em um lugar definido, garantindo nesses espaços tanto a sua presença quanto o seu controle. E, embora essa passagem não se refira especificamente aos discursos sobre a inclusão escolar nem às práticas ditas inclusivas utilizadas pelos atores dessa instituição, neles ainda se vê reverberar as demarcações desse modelo que não trata mais de rejeitar, mas de incluir.

Nas palavras de Foucault (idem, p. 40), esse modelo nasce com o propósito "de maximizar a saúde, a vida, a longevidade, a força dos indivíduos", criando um "campo de regularidade" que possa permanecer em constante exame e "no interior do qual se vai avaliar sem cessar cada indivíduo, para saber se está conforme à regra, à norma de saúde que é instituída". Com a sua emergência se inventaria na Idade clássica "as tecnologias positivas de poder", isto é, se passaria de "uma tecnologia de poder que expulsa, que bane, que marginaliza, que reprime" a um "um poder que fabrica", que observa, que sabe e "que se multiplica a partir de seus próprios efeitos" (idem, p. 41). Dessa forma, se teria criado um poder "que não age por exclusão, mas sim por inclusão densa e analítica dos elementos", nem "age pela separação em grandes massas confusas, mas por distribuição de acordo com as individualidades diferenciais", tampouco estaria ligado "ao desconhecimento, mas, ao contrário, a toda uma espécie de mecanismos que asseguram a formação, o investimento, a acumulação, o crescimento do saber" (idem, ibidem).

Graças a essas formas emergentes de poder as suas práticas, técnicas, enfim, as suas artes "podem ser transferidas para suportes institucionais muito diferentes, como os aparelhos de Estado, as instituições, a família, etc.", distribuindo-se em diversos campos de governo, como o das crianças, o dos loucos, o dos pobres e, gradativamente, o dos operários (idem, p. 42). É assim que, desde a Idade clássica, inicia-se uma distribuição das artes de governo e das tecnologias do poder que, antes de excluir, subjugam determinados tipos de sujeitos à normalização de suas condutas, de seus comportamentos e de suas vidas. Dessa maneira, a normalização passaria a ser o fim daqueles dispositivos de subjetivação, produzindo seus efeitos sobre as vidas individuais, porém empreendidos por um processo social geral, desenvolvidos no domínio da educação por instituições como a escola, no da medicina com os hospitais, no da produção industrial com as fábricas, no da força policial com o exército.

Para essas tecnologias positivas do poder, na qual se encontram as pistas de toda uma genealogia dos discursos sobre a inclusão e das práticas ditas inclusivas, a norma assume função política. Ela funciona como uma espécie de princípio de 
inteligibilidade, por um lado, em virtude de sua associação aos saberes pedagógicos, médicos ou biológicos, psiquiátricos, econômicos e sociológicos; por outro, na medida em que produz tecnologias responsáveis pela correção daqueles que se encontram além ou aquém da normalidade, com o intuito de qualificá-los e de torná-los produtivos. Nisso consiste uma "espécie de poder normativo" que procura regular as condutas individuais e que se exerce, no Estado moderno, por meio de diversas artes de governo, no intuito de prolongar e beneficiar as vidas com uma série de tecnologias, denominadas biopoder, que por sua vez se executa na forma de uma anátomo-política do corpo, por um lado, e de uma biopolítica da população, por outro, nos termos analisados por Foucault $(1997,2008,2010)$. Biopoder e biopolítica constituem-se, assim, em categorias de análises importantes para se compreender as condições de emergência dos discursos sobre a inclusão e, particularmente, o modo como se manifestam na escola.

A maneira como as tecnologias do biopoder operam na escola e se entrecruzam com outras práticas emerge mais ou menos na Idade clássica, assumindo a função de normalizar vidas específicas, ainda em seu início - vidas infantis -, regulando os excessos que aí emergem e, não sem alguma resistência, subjugando-as dispositivos de uma arte de governo pedagógica das crianças que as modela de acordo com uma norma, um olhar e uma subjetividade adultos (Pagni, 2010). Quando os excessos ultrapassam a normalidade estabelecida e adentram esse ambiente institucional, manifestando em seus acidentes e em suas contingencias, experienciados em suas singularidades e existentes em suas diferenças, são vistos, primeiro, como monstruosidades a serem segregadas, tal como se pensava até a Idade clássica, e depois classificados como anomalias que, ao necessitar de correções antes do que segregação, produzem as tecnologias positivas do poder, nos termos em que se configuraram a partir do século XIX.

No intuito de corrigir os desvios com que se apresentem, de acordo com normas e tecnologias provenientes dos saberes médicos e pedagógicos vigentes, a criança é assumida a essa época pela escola, porém não sem contar com o apoio de outra instituição primordial. Cabia à família se "encarregar do corpo e da vida dos filhos" para que, depois de garantir sua sobrevivência e vigilância, o Estado, por intermédio de seus aparelhos - especialmente da escola-, se incumbisse diretamente de exercer a função de conduzir a sua alma e governar o seu corpo. Inspirada em uma "espécie de cruzada pela educação natural das crianças" (Foucault, 2010, p. 222), isto é, em uma ideia de que caberia aos próprios pais educarem seus filhos, não sem a interferência de saberes como os médicos e a pedagogia, até o momento em que o Estado os educasse, a arte de governo pedagógica exercida nas escolas e as tecnologias que a constituem recebem certo influxo da "descoberta da infância pela psiquiatria”, nos termos desenvolvidos por Foucault (idem, p. 266).

Isso implica compreender a infância objeto de seu governo não apenas como tempo de vida com características próprias, certos padrões de desenvolvimento e ritmos de aprendizagem, como também, e principalmente, como um "filtro para analisar comportamentos" e, portanto, uma suposta origem de todas as doenças mentais, dos desvios e das anormalidades manifestas na juventude ou na adultez. São essas últimas tendências errantes da vida que devem ser tratadas e corrigidas 
desde a infância, quando diagnosticadas na educação familiar e, particularmente, pela escola, antes que qualquer tipo de monstruosidade manifeste-se na vida adulta e se rebele com a sua emergência na deformação da população.

Em vez de expulsar o monstro da escola ou de relegá-lo ao seio da própria família, graças aos saberes médicos e psiquiátricos que se interpõem à educação das crianças a partir do século XIX, a arte de governo pedagógica as classifica em normais e anormais, para melhor aproveitar as capacidades dos primeiros e corrigir as incapacidades dos segundos de modo que se possa homogeneizar a população, ainda que seja para criar instituições específicas para esses últimos e completar a rede em torno da qual se exerce a educação pública.

Essa tática adotada pela escola, em geral, é acompanhada de campanhas e estratégias eugênicas em outras instituições civis e estatais, com o intuito de regular e normatizar os casamentos, as misturas raciais, com um forte apelo a taxas demográficas, ao embranquecimento racial, como se vê, entre outros países, no Brasil, em meados do século XX. Não se trata, com isso, de expulsar os incapazes por anomalias ou por inferioridade racial ou por cruzamentos genéticos interfamiliar, mas de conceder-lhes um lugar na hierarquia social, ainda que seja em um nível inferior que dificilmente possa ser superado, justificando essa inferioridade biológica, antropológica ou geneticamente.

Considerável parte da literatura sobre educação especial, embora pouco tenha como referencial de análise essa perspectiva teórica, aborda essa divisão e hierarquização proporcionada pela educação dos anormais como parte de uma história que aos poucos foi sendo ultrapassada no que diz respeito à nomenclatura, a políticas públicas e, até mesmo, tecnologias cada vez mais produtivas, menos estigmatizantes (Bueno, 2004). Na verdade, não é raro se demarcar aí algumas condições históricas, se não da emergência dos discursos sobre a inclusão escolar e das práticas inclusivas que legitimam, ao menos o nascimento do campo de estudos hoje conhecido como educação especial. Embora os discursos e práticas sejam historicamente mais recentes que esse campo no Brasil, não deixa de reverberar ao olhar que trazem para falar da inclusão e de suas práticas alguns dispositivos discursivos ou normalizadores que reiteram essa forma de exercício do poder e da governamentalidade, mesmo após a biopolítica e as tecnologias do biopoder se terem reformulado diante das tendências atuais do neoliberalismo.

Antes de analisar a reformulação da biopolítica e do biopoder pela ótica foucaultiana, é interessante exemplificar como os discursos sobre a inclusão e as práticas inclusivas na escola continuam a repercutir o "exercício do poder normativo", e não somente entre os profissionais da educação especial, mas também entre professores e pais. Mesmo por esse enfoque, os deficientes são separados por suas deficiências, pelas curvas de normalidade de seu crescimento, desenvolvimento e aprendizado, quando não por dispositivos bioquímicos para remediar suas dores, convulsões, acelerar a capacidade cognitiva, entre outros, de modo que se possa aproximá-los o mais possível de uma norma da deficiência para, então, compará-la aos padróes de normalidade da pessoa supostamente normal.

Nesse ciclo sem fim de normatividade, os saberes científicos, as técnicas terapêuticas e as tecnologias pedagógicas vão sendo aplicadas pelos profissionais 
especializados sobre as pessoas ditas especiais, em parte significativa dos casos vistos em suas deficiências como elementos sobre os quais querem ver as correções e os resultados de uma ação, mas raramente pelo que são como atores desse processo. Os discursos sobre a inclusão conclamam que se olhe para esses elementos do mesmo modo que se olha para os sujeitos normais e, portanto, aspirar ver neles, se não certa normalidade, ao menos uma funcionalidade para o mundo em que vivem.

Essa visão não é muito diferente da visão da maioria dos pais ou familiares dos indivíduos ditos especiais, que, premidos por aquele ciclo normativo e por um mundo em que todos devem ser produtivos e ocupar um lugar no sistema econômico para que possam ser reconhecidos socialmente, acabam também por exigir de filhos diferentes de si uma normalidade e funcionamento semelhantes aos seus, com certo desconto para a deficiência deles, porque de antemão presumem que não têm chances de disputar o topo, mas podem desempenhar, com adaptações, alguma das funções na escala hierárquica dos ofícios. Caso não se abandone a priorização da norma, a univocidade da lógica da identidade e a pretensão da ordem hierárquica com que o mundo é percebido, os deficientes continuarão sendo vistos - quando não forem tratados como objetos de saberes e de tecnologias utilizados para torná-lo um elemento produtivo no sistema - com preconcepções de sujeitos-pacientes de uma correção pelos terapeutas, sujeitos-alunos de uma capacitação ou de uma informação pelos professores e sujeitos-filhos de uma aspiração pessoal pelos pais.

Isso não quer dizer que se deva abandonar a norma, a lógica e a ordem em termos absolutos, tampouco as conquistas científicas e tecnológicas desse campo, mas sim combater a sua conversão em regulamentos, saberes e racionalidades que se apresentam como regimes de verdade únicos e para os quais esses seres-deficientes seriam apenas elementos ou objetos a serem incluídos, jamais atores ou sujeitos. Isso porque sua atuação no mundo para exprimir seu modo de ser e de estar, assim como o tipo de relação que tem com a vida, consigo e com sua diferença, por essa ótica, parece ser mediada por um outrem, sejam eles profissional, professor ou familiares, supostamente superiores em sua capacidade, que por eles falam, ainda que nem sempre os vejam e, quando os veem, mascaram sua diferença dos demais para torná-la assimilável pela maioria. É como se, na proteção desse outro, protegessem a si mesmos, a hierarquia social na qual tomam parte e, com isso, o próprio sistema, preservando esses indivíduos da diferença contestatória de sua identidade, da ruptura com os fundamentos do poder no qual se assenta e da vida que transborda a funcionalidade, assim como desestabiliza o existente.

Mais que uma consequência do desenvolvimento dos saberes e das formas de exercício do poder, tal problema parece constituir-se em um caso ético da democracia no Ocidente. De acordo com Foucault (2012), desde sua genealogia, a democracia constituiu-se em uma "isonomia quantitativa" na qual a maioria comanda, enquanto a "diferenciação ética" decorrente das relações agônicas dos grupos minoritários contraria, afronta e resiste ao majoritária e quantitativamente definido. Para se manter essa posição majoritária assim constituída, um dos mecanismos da democracia é invisibilizar, marginalizar e excluir os devires decorrentes dos modos de vida minoritários, ainda que sob o pretexto da inclusão. Por sua vez, esses devires invocam uma transformação daquela isonomia quantitativamente construída ao 
expressarem publicamente os diferentes modos de vida, colocando-a em xeque e, paradoxalmente, tensionando-a.

Esse paradoxo da democracia é agravado em seu desenvolvimento, no Ocidente, sobretudo após a modernidade, que, em vez da mobilidade propiciada pelas minorias e pela "diferenciação ética" que a compreende, tendeu a pautar-se na estabilidade e, por mais que propague uma aparente pluralidade de interesses, em uma fixidez que subjuga a vida a uma organização eminentemente econômica, destituindo-a onde procura vigorar. Se o liberalismo político protagonizou esse fluxo de interesses individuais, centrando-o em uma espécie de identidade lógica, o advento do neoliberalismo o traduziu em uma racionalidade de cálculo e da indiferença gerada pela expansão da ciência econômica, presumidos como o novo reino da individualidade, supostamente livre das ingerências do Estado, mas gerido por formas de governamentalidades capitaneadas pelo mercado e pelas forças do capital monopolista.

\section{EMERGÊNCIA DAS POLÍTICAS DA INCLUSÃO ESCOLAR NA BIOPOLÍTICA NEOLIBERAL}

Ao analisar as relações do neoliberalismo com a biopolítica, em seu curso Nascimento da biopolitica, Foucault argumenta que aquelas se configuram nos Estados Unidos, a partir da segunda metade do século XX, como "uma maneira de viver e de pensar", "um tipo de relação entre governantes e governados" (e não de uma técnica dos primeiros sobre os segundos), em que o "problema da liberdade" se impõe sem que se reduza propriamente ao modo de ser dos direitos e dos serviços públicos (2008, p. 301). Gradativamente, se veria essa forma de vida assumir uma "reivindicação global”, porém se radicalizando em um modo de administração econômica que penetrou nas esferas ínfimas da vida humana, tornando-a parte de um capital e da constituição de um homo oeconomicus que não mais se empreende pela troca, mas no investimento e no empreendimento sobre si mesmo.

Na composição desse si a ser empresariado, é possível reconhecer as limitações e as potencialidades a serem exploradas em sua máxima capacidade e eficiência, em uma avaliação minuciosa e decisiva sobre si e os demais indivíduos. Produzida graças ao desenvolvimento técnico-científico e à ciência econômica, tal avaliação permite o reconhecimento dos elementos inatos e o que pode ser adquirido pelos indivíduos, exigindo o máximo de produtividade e de eficiência de cada um, ao saber até onde a sua máquina-competência pode chegar, quais são seus eventuais desgastes e capacidades.

Dos elementos inatos ou hereditários relatados pela biologia ou, até mesmo, pelo atual desenvolvimento da genética, esse indivíduo poderia mapear como as tendências herdadas interfeririam nas escolhas, limitariam ou incrementariam o equipamento de cada um para ser mais bem explorado e para torná-lo produtivo de acordo com esse diagnóstico. Afinal, diz Foucault: "um dos interesses atuais da aplicação da genética às populações humanas é possibilitar reconhecer os indivíduos de risco e o tipo de risco que os indivíduos correm ao longo de sua existência” 
(idem, p. 313). Com esse interesse genético, parece ser possível mapear quais são os indivíduos de risco e os riscos de relações destes com outros seres capazes de perpetuá-los ou minimizá-los, definindo aqueles que possuem "bons equipamentos genéticos" e, consequentemente, produzirão indivíduos de "baixo risco ou cujo grau de risco não será nocivo, nem para eles, nem para sociedade" (idem, ibidem), constituindo-se em matrizes raras que ingressam, frequentemente, no cálculo e tornam-se uma alternativa ao investimento econômico.

O mesmo se pode dizer da classificação dos indivíduos que implicam alto risco em razão de seus genes, em que sua reprodução necessite ser monitorada para evitar seu perpetuamento e que seu equipamento genético, salvo não possa ser aprimorado, requeira maior controle no intuito de conduzi-lo ao exercício de funções sociais que exigem um baixo risco, pouca responsabilidade. Embora a inquietação com esse interesse econômico da genética traga tantas preocupações, na acepção de Foucault não se trataria mais de compreendê-la "nos termos tradicionais dos racismos", pois se ocupa de um problema político atual: o de "constituição, de crescimento, de acumulação e de melhoria do capital humano" (idem, p. 314). Esse é o interesse em torno do qual a genética ganha relevo entre os saberes e tem o seu investimento assegurado pela ciência econômica, pois auxilia a naturalizar a vida e a despolitizar as relações de poder que a compreendem, assumindo uma das formas de fascismo atual quando seu uso extremado justifica as exclusões de certas deficiências e déficits, apoiando certos estados de exceção.

Tão importante quanto essa composição do si mesmo a ser empreendido como forma de avaliação dos riscos e para a formação do capital humano, porém, são os investimentos em seu aprimoramento ao longo da vida ou a sua qualificação para disputar um lugar no mercado, tal como tem sido frequentemente destacado como importante estratégia do neoliberalismo. Para formar "essas espécies de competência-máquina que vão produzir renda", é necessário, segundo Foucault, “investimentos educacionais", isto é, não apenas a "instrução propriamente dita" ou o "aprendizado profissional", desenvolvido na escola, mas a formação dos "elementos que entram na constituição de um capital humano", "muito mais amplos" e "mais numerosos" que esse tipo de instrução e aprendizado (idem, p. 315).

No cálculo desses investimentos entram, em particular, entre outros aspectos, desde o "tempo de afeto consagrado pelos pais a seus filhos", passando pela cultura dessa família e pelos estímulos ambientais, até os cuidados médicos e de higiene para garantir, mais que a formação do capital humano, o seu aprimoramento para que possa ser "conservado e utilizado pelo maior tempo possível" (idem, p. 316). Trata-se, portanto, de aprimorar e conservar o capital humano, de formá-lo cercando-o de cuidados psicológicos, pedagógicos e médicos para que desempenhe efetivamente uma função econômica, fazendo com que aquele adentre as análises para o bom funcionamento desta, mas sem deixar que se estratifique a mobilidade do indivíduo no que se refere ao empreendimento de si mesmo. Isso faz com que, quanto mais se invista em si mesmo, no que se entende como capital humano, mais se necessite continuar investindo, até o final da vida ou o esgarçamento das forças vitais, sendo esse um imperativo da existência que se apresenta a todos como um limiar entre a vida e a morte, ou seja, em outras palavras: o viver como sinônimo 
da mobilidade própria daquele investimento e empreendimento de si, enquanto o morrer é entendido como similar à imobilidade e à exclusão de quem está fora dessa meta (Duarte, 2010).

Nessa atual conjuntura, a mobilidade passa a ser constitutiva de um investimento importante, como ocorre nos casos de migração dos indivíduos, dando-lhe a impressão de que dessa maneira ampliariam seus recursos e qualificações ou até mesmo seu senso de liberdade, quando na verdade apenas respondem a certo princípio concorrencial do mercado e se enredam em seu jogo. Afinal, a busca de um ponto cego tanto do mercado quanto dos acontecimentos que atravessam a existência dos indivíduos começa a entrar no cálculo da busca de "inovações" nos mais diferentes campos, como uma marca global do neoliberalismo, para propiciar uma impressão de mobilidade produzida por um "sistema de diferenças" e uma aparente unidade capaz de aplacar os efeitos dessa economia da vida, que a torna escassa justamente onde transborda. De acordo com Foucault (2008, p. 354-355), tem-se nesse horizonte de análise:

[...] a imagem ou a ideia ou o tema-programa de uma sociedade na qual haveria otimização dos sistemas de diferença, em que o terreno ficaria livre para os processos oscilatórios, em que haveria uma tolerância concedida aos indivíduos e às práticas minoritárias, na qual haveria uma ação, não sobre os jogadores do jogo, mas sobre as regras do jogo, e, enfim, na qual haveria uma intervenção que não seria do tipo da sujeição interna dos indivíduos, mas uma intervenção de tipo ambiental.

É nesse contexto global que as práticas ditas inclusivas aparecem no âmbito da ação política pública, com vistas a garantir o direito das minorias, sob o influxo de movimentos sociais que empreenderam muitas vezes dentro de uma lógica identitária e, lamentavelmente, de uma economia do capital humano que procura valorizar as diferenças naquilo que pode favorecer as inovaçôes, a eficiência no empreendimento de si e, enfim, favorecer a mobilidade do mercado. Por sua vez, os discursos sobre a inclusão aparecem aí, quase sempre, preservando sua lavra funcionalista e, principalmente, centrando-se no apelo à garantia de condições (econômicas, de acessibilidade, de igualdade étnico-racial, de gênero etc.) para intervir sobre o ambiente a fim de que cada um possa empreender sobre si mesmo, algo que geralmente se faz pelo investimento educacional recebido tanto da escola quanto da família.

Os cálculos sobre as potencialidades dos componentes hereditários a serem transformadas em atos, das capacidades a serem desenvolvidas graças ao treinamento de habilidades, a aquisição de conhecimentos e a incorporação de hábitos, em ambas as instituições, constituem-se em variáveis importantes na avaliação dos riscos do investimento do capital humano de cada indivíduo. No caso da escola, essa avaliação se dá por uma escala que privilegia o desenvolvimento de capacidades, o treinamento de habilidades e a aquisição de informações necessárias para o acúmulo de capital humano destinado à ação eficiente nos níveis superiores de ensino, ao consumo informado e à qualificação profissional. Para essas tarefas concorrem outros aparelhos estatais e dispositivos de sujeição da sociedade civil, 
inclusive a mídia, que facultam aos indivíduos, mapeados com maior potencial e menor risco ao investimento educacional, uma ampla gama de possibilidades para constituírem-se em empresários de si, incorporarem uma economia e se perfazerem em um capital humano. Ao mesmo tempo, esse capital humano torna-se objeto de troca no mercado e produz satisfação pessoal no sujeito econômico, que passa a ser julgado por si e por outrem em razão de sua eficiência, de seu desempenho e de sua performatividade, ou seja, por medidas ou por regras supostamente iguais para todos, mas que instauram um jogo que somente alguns se sobressaem em virtude de seus esforços, interesses, capacidades e, principalmente, competências.

Em torno desses resultados almejados pelo investimento educacional se alinham a escola e a família - contudo, ajustam-se a essa racionalidade para qualificar e capacitar seus elementos para que também se tornem sujeitos econômicos. A esses sujeitos-elementos são oferecidas as condições para que alcancem o grau máximo possível para si mesmo no jogo concorrencial existente e demandam-lhes que mobilizem todas as forças e potencialidade disponíveis para melhor se empreenderem no mercado. O pressuposto que justifica essa demanda é o de que, desde a infância até a sua emancipação jurídica, são ofertadas a esses elementos as condições materiais, afetivas e, principalmente, informacionais para que correspondam a essa exigência de mobilização, em uma aposta da escola e da família em sua capacidade, em seu desenvolvimento cognitivo, desempenho e performatividade. Em torno de tal justificativa dos discursos sobre a inclusão, ocorre uma espécie de preparo ambiental, realizada em virtude das intervenções familiares e escolares, para que suas potencialidades e capacidades frutifiquem, tal como em todo capital humano no neoliberalismo, propiciando ganhos a outrem e satisfação a si.

Desde o nascimento até o momento em que adentram o ensino superior ou a vida pública - nesse caso o mercado de consumo e, depois, de trabalho entendido como um dos sinais de emancipação do sujeito econômico -, tais intervenções são medidas pelos cálculos de risco no investimento em cada indivíduo, sendo objetos de avaliação, elaboração e efetivação, levando-se em conta a composição de cada "máquina", suas competências e capacidades.

Parece ser desse modo que estratégias desenvolvidas por essas instituições garantem a distribuição dos investimentos conforme as capacidades de cada qual, almejando o seu máximo rendimento, ao mesmo tempo em que as sua práticas procuram oferecer as condições de igualdade inicial e juridicamente instituída, necessárias a toda concorrência para que, por um lado, aos diagnosticados como menos capazes, ou mesmo como incapazes, existam condições compensatórias para atuarem, ainda que como coadjuvantes nos ganhos de outrem e na satisfação de si. Por outro lado, em tais práticas, a atuação dos mais capazes ou capacitados no processo de empreendimento de si lhes conferiria o papel de protagonistas, já que estrategicamente a eles estaria destinada a capacidade de inovação, produzindo a mobilidade própria dessa configuração da biopolítica no neoliberalismo, a saber: a criação de novos produtos capazes de ampliar os ganhos de outrem, a renda para si e, consequentemente, a sua própria satisfação. As diferenças são diagnosticadas, assim, em virtude desse escalonamento de capacidades individuais que, economicamente, fazem funcionar melhor o jogo da livre concorrência, des- 
centralizando por meio da multiplicação de suas artes de governo a intervenção do Estado, que apenas reage às reivindicações das minorias para regular a vida da população e para apoiar a esse investimento educacional no intuito de propiciar a sua distribuição compensatória para cada indivíduo e de garantir os preceitos jurídicos de igualdade naquele jogo.

Ainda que na esfera pública sejam consonantes, a maioria das vezes, com os objetivos do jogo do mercado, aquelas reivindicações e essa intervenção estatal constituem-se em condições de emergência das políticas de inclusão no jogo concorrencial próprio do neoliberalismo. Isso porque forçam a alteração das regras desse jogo para corrigir eventuais desigualdades suscitadas por condições de diferenciação entre seus jogadores - em razão de suas condições genéticas, físicas, cognitivas, psicológicas, econômica, étnico-racial, de gênero etc. -, instituindo práticas que visam manter certo equilíbrio na consecução da eficiência dos lances, na inovação das estratégias e na mobilidade daqueles que se alteram em protagonizar as jogadas, ampliando os ganhos de todos da mesma equipe e, ao mesmo tempo, a satisfação propiciada pelo consumo de cada um.

No entanto, nem essas práticas produzem esse equilíbrio em razão do descompasso existente entre a previsibilidade das jogadas e o imprevisível dos lances, nem a diferença dos jogadores pode ser dirimida por alterações de regras que almejam corrigir as desigualdades, sobretudo quando o objeto da regulamentação não é totalmente passível de comparação por assimilação ou abstração, nem por uma lógica identitária ou um cálculo econômico, mas sim conduzido por um sujeito impassível, errante e imprevisível como a vida.Justamente por isso esse sujeito capaz de criar modos de existência outros para melhor habitar eticamente o mundo teria como sua condição ontológica a liberdade, como sua virtualidade a assunção de uma atitude vital e como resultado a diferenciação produzida por essa experiência.

É esse sujeito ético que as políticas de inclusão procuram, por um lado, tornar presente no que se refere às condições de capacitação e às potencialidades de suas capacidades e, por outro lado, fazê-lo invisível em suas diferenças e calar-se em relação às suas resistências, enquadrando-o em um jogo no qual as regras se alteram para que seus resultados reflitam sobre o ganho de outrem e sobre a satisfação pessoal de cada um.

O que permanece intacto nesse jogo é o esvaziamento da existência de sentidos para reduzir a vida à sua racionalização, sequer lógica e somente econômica. Não se trata mais, desse modo, de incluir para requerer desses sujeitos que se diferenciam como anormais apenas a sua presença como objetos, mas sim como sujeitos que participam ativamente desse jogo com suas capacidades, qualificações e limitações, subjugando-se, mais que às suas regras para poder simplesmente jogar, a um dispositivo de inclusão que independe da expectativa de outrem em relação ao seu desempenho. Ao cumprir esse papel previsível no jogo, porém, esse sujeito deveria deixar de ser o que é e de diferenciar-se eticamente dos demais, escondendo o si mesmo no empreendimento de um eu esperado socialmente, justamente para ser aceito como se houvesse somente a racionalidade econômica, uma lógica unificadora da pluralidade dos modos de habitar o mundo, definida por uma justificação seja natural, seja transcendental, seja histórica. 


\section{EM BUSCA DE UM OLHAR MAIS RADICAL}

Ao adotar um desses pontos de vista, os discursos sobre a inclusão escolar prometem fazer inclusão nesses termos, por um lado, instituindo um direito para neutralizar as lutas em torno da afirmação da vida e da diferenciação ética; por outro lado, acirrando a disputa entre seus próprios jogadores dentro desse jogo e fazendo valer a força de exceção, de exclusão, de segregação, daqueles que ocupam uma melhor posição - majoritária - sobre aqueles que estão supostamente em um nível abaixo do seu. A instituição dos direitos civis ameniza as lutas empreendidas por essa população que se sente excluída em razão de fatores que a diferenciam dos demais integrantes da população, na medida em que se acomodam as regras para lhe dar condições de presença no jogo, ainda que seja para cumprir o papel antes mencionado, sobretudo porque parece ser difícil colocar esses sujeitos à margem dos objetivos da livre concorrência e de sua restrição a uma racionalidade econômica a qual os jogadores estão enredados. Para alguns jogadores, o discurso da inclusão, com as alterações das regras, traz certa promessa de salvação, de pertença e de conquista, ainda que suas diferenças permaneçam nas formas de cor de pele, de pertencimento a um gênero, de uma deficiência, de um trauma, de uma condição sociocultural ou socioeconômica.

Embora essas demarcações do que são independam de suas vontades e caracterizem em certa medida seus estilos de existência, aquelas promessas procuram, provisoriamente, deslocar de si para o outrem a vontade e a caracterização de seu modo de ser, produzindo o apaziguamento das forças que mobilizam internamente e das lutas que travam com os seus e contra os demais. Os outros integrantes da população, por sua vez, quase sempre se incomodam com as alterações das regras que já os favoreciam e continuam a favorecer, por considerar uma intervenção externa, alheia a sua vontade e que the custará alguma mobilidade no jogo, mais para o lado, raramente para baixo, na hierarquia concorrencial.

Bastaria a lembrança das políticas de cotas raciais e socioeconômicas para o ensino superior ou mesmo as de inclusão escolar na educação básica, no Brasil, para se compreender tal referência como uma reação tanto àquela intervenção quanto a essa ameaça de suposta mobilidade. Esse sintoma indica quanto a maioria acostumada a esse jogo, mesmo admitindo a alteração de suas regras, raramente se dispõe a mudar suas condutas, mesmo que seja para melhor alcançar seus objetivos imediatos. Por isso, as disputas se acirram no âmbito do jogo, pois os demais integrantes da população veem nessa necessária alteração das condutas uma ameaça a sua integridade enquanto sujeitos econômicos, com posições já definidas no jogo e com um desvio no que se refere ao empreendimento de si, chamando atenção para o fato de que existe algo além do investimento que fazem em seu capital humano ou, até mesmo, no de seus filhos.

É comum ouvir de alguns pais queixas de que os alunos deficientes nas escolas, os quais foram recém-incluídos por força de lei, atrapalhariam o rendimento de seus filhos, retardando o aprendizado ou, ao menos, não permitindo o treinamento da máxima eficiência das capacidades deles. O que significaria admitir, na lógica da racionalidade econômica imperante, que seus filhos, supostamente normais, 
estariam sendo prejudicados pelos chamados deficientes e tendo perdas no investimento educacional destinado a constituir o seu capital humano. Embora não seja exatamente esse o argumento, pais dizem que, mesmo apresentando menos riscos por suas condições hereditárias ou genéticas e, portanto, mais potencialidades para o desenvolvimento pleno de suas capacidades, seus filhos ficam à mercê de práticas inclusivas nessa instituição que, ao concordar com o discurso sobre a inclusão, atrasaria o ritmo de aprendizados e amenizaria a intensidade de treinamento para que as outras crianças desenvolvessem as competências necessárias para sua constituição como capital humano e para apresentarem-se como empresários de si.

Com vistas a considerar os riscos do investimento educacional, esses pais dizem que seus filhos perdem economicamente com essa relação com o incapaz ou o chamado deficiente, assim como eles, pois - ainda que por meio de outras esferas invistam para que seus filhos alcancem a esse fim -, sentem-se não eficientes na gestão do capital humano de sua prole. Tal sentimento também ocorre com pais de filhos deficientes, porém por outras razões. Afinal, a realidade da relação com seus filhos thes impõe a percepção da necessidade de maior investimento, pois seus filhos estariam sujeitos a um maior risco, segundo essa racionalidade, na medida em que a sua composição hereditária apresenta problemas genéticos, congênitos ou mesmo limitações físicas e/ou intelectuais decorrentes de acidentes, que restringem suas capacidades, antes mesmos de serem desenvolvidas pelo seu treinamento, administração e aquisições advindas da educação. Não raro esses pais se sentem ineficientes, até mesmo como pais, ao perceberem as incapacidades de seus filhos em se empresariar por si mesmos e, por vezes, ao perceber na deficiência deles as suas próprias.

Tal sentimento parece substituir a vergonha de gerações anteriores, impulsionando esses pais a uma busca desenfreada pela normalidade, por correções, a ponto de vibrarem com qualquer conquista nessa direção e resignarem-se, uma vez que, em virtude da segurança perante os riscos da condição de deficientes de seus filhos, já seria um ganho ocuparem uma posição menor na hierarquia funcional instituída. Tal é o aprisionamento a determinada lógica e sentimentos que raramente esses pais pensam que o eventual ganho de seus filhos seria pequeno se comparado a de outros alunos, chamados de normais, que aprendem com a convivência com a deficiência de outrem e com as relações aí estabelecidas, algo que escapa ao poder disciplinar, à normalização ou até mesmo à capacitação almejada pela educação escolar.

Não é nesse âmbito de preocupações que se pauta atualmente o discurso sobre a inclusão escolar, que teve como condição de emergência a racionalidade econômica e a biopolítica neoliberal, mas, sem sombra de dúvidas, poderia ser. Quando emergem por essa ótica, os acidentes desse outrem e as diferenciações trazidas por sua deficiência para os atores da escola seriam ao menos tomados como objetos de estudo, de planejamento e de cálculo para promover a inovação das tecnologias do biopoder presentes na escola, assim como propiciar maior mobilidade ao capital humano formado nessa instituição, para admitir a diferença ética e se confraternizar com ela, tornando o mundo cada vez mais inclusivo.

Para além das restrições à disciplinarização, à correção, à normalização e à capacitação desses atores da educação escolar, essa perspectiva radicaliza o papel da 
instituição escolar na formação do capital humano, dando-lhe poderes mais amplos e investindo na relação dos demais alunos com o deficiente. Isso porque visa fazer dela um preparo empírico para que os alunos ditos normais adquiram habilidades para lidar com a diferença do outro no presente, ampliando seu capital humano para que possa usar os recursos aprendidos com essa relação em um futuro próximo, enquanto o deficiente com ela garantiria o aprendizado de sua subsistência autônoma, contando com a tolerância alheia e com políticas compensatórias pactuadas desde o presente e a serem ampliadas no futuro.

Desse ponto de vista, os discursos sobre a inclusão poderiam vencer algumas resistências e, se apropriados pelos pais dos alunos com deficiência, poderiam convencer os demais de que o principal beneficiário da introdução das práticas inclusivas, efetivamente, seriam os filhos dos outros, já que os seus apenas teriam ganhos secundários, mas ao menos estariam protegidos da exclusão e da violência que esse jogo representa. É em torno de tais argumentos que alguns profissionais que atuam com crianças e jovens deficientes vêm enunciando de outro lugar o discurso sobre a inclusão, sendo acompanhados por alguns pais. No entanto, esse outro lugar de enunciação parece corroborar e aperfeiçoar essa ótica atual do mercado e do capital humano, reiterando uma racionalidade econômica que, embora se tenha instituído profundamente nos capilares da vida atual e, especialmente, de seu controle pelas tecnologias do biopoder, não parece suficiente para que a diferenciação ética que compreende a deficiência torne-se visível e nela se veja não uma vida que se esvai, mas uma experiência singular que potencializa e resiste a sua destituição nas relações de poder vigente.

Para que isso acontecesse, seria importante que de sujeito participante do capital humano que, com todas as suas limitações, empreende a si próprio e ocupa um lugar no jogo hierárquico do capital, tal como proposto pelo discurso sobre a inclusão, os deficientes passassem a assumir uma posição, se não de sujeitos da enunciação desse discurso, ao menos daqueles que asseguram a sua expressividade na esfera pública, um lugar mais digno para ocupar-se de si mesmo e de exprimir sua diferença ética no âmbito de uma isonomia quantitativa de opiniões. Poderiam apresentar-se dessa forma como enunciadores de um discurso da diferença ou simplesmente como sujeitos que exprimem uma deficiência, entre tantas existentes, inclusive em cada um de nós e nas quais impulsiona a vida. Esse ponto de vista daria maior visibilidade ao que são, ao sujeito ético que perfazem, ainda que se encontre aí um limiar extremamente complexo e delicado, assim como se apresentaria dessa forma um contraponto tanto ao discurso sobre a inclusão quanto às práticas ditas inclusivas, nos termos de sua biopolítica neoliberal.

Esse limiar é complexo porque implica uma passagem da inclusão para a diferença, marcada por outro tipo de racionalidade, e delicado porque necessita da implicação de cada um no intuito de ocupar-se com as condutas que conduzirão a própria vida, em uma relação com a deficiência que é de outrem, mas que também é sua, de cada um e de qualquer comunidade. Tal delicadeza consiste em andar no fio da navalha, entre uma vida que se esvai pelo atual exercício das tecnologias do biopoder, a racionalidade econômica, e outra que foge dessas últimas, sobrepondo-se, restando ou excedendo a ela, por outras racionalidades. Em que medida se pode 
caminhar nessa linha, sabendo quando se tem o direito de usar do desenvolvimento dos conceitos e das ciências para conduzir a vida sobreposta, restante ou excedente, é uma das incógnitas dessa política que tem como base uma série de questões éticas ou bioéticas - e talvez um de seus desafios mais dignos de serem enfrentados no tempo presente.

Entre as questões que desafiam aqueles que se relacionam forçosa ou deliberadamente com esse outro, chamado de deficiente, por um lado, é o de ver na experiência singular que essa relação proporciona a emergência de uma diferença radical e de um acontecimento que problematiza a sua própria existência e faz dessa deficiência alheia um devir da transformação de si mesmo; por outro lado, para esses com quem se relacionam, o desafio parece o de se esse sujeito chamado deficiente pode ou não, como qualquer um, pelas limitações genéticas, biológicas ou acidentais que a ele se impõe, se não se emancipar desse estado, ao menos exprimir a diferenciação ética em que vive, entre as tantas outras que se apresentam na esfera pública. Cabe perguntar se essa diferenciação que exprimem não seria a possibilidade de transformar as próprias formas de existência hegemônicas nas comunidades das quais participam e da própria esfera pública, exigindo uma democracia que não se paute exclusivamente em uma isonomia quantitativa, mas também na valorização da convivência agônica e qualitativa de diferentes modos de existência, elegendo-o como seu princípio vital e como uma maneira de resistir à atual configuração da biopolítica.

Esses desafios, sim, parecem conferir positividade à deficiência e dignidade aos deficientes como efetivos partícipes da vida e de suas lutas no mundo, dando-lhes se não um lugar de destaque, ao menos um lugar comum.

\section{REFERÊNCIAS}

Bueno, J. G. S. Educação especial brasileira: integração/segregação do aluno diferente. 2. ed. São Paulo: Editora da PUC/SP; EDUC, 2004.

Duarte, A. Vidas em risco: crítica do presente em Heidegger, Arendt e Foucault. Rio de Janeiro: Forense Universitário, 2010.

Foucault, M. História da sexualidade: vontade de saber. v. I. Rio de Janeiro: Graal, 1997. . Introdução à vida não fascista. In: . Por uma vida não fascista. São Paulo: Sabotagem, 2004. p. 4-8. Nascimento da biopolitica. São Paulo: Martins Fontes, 2008. Os anormais. São Paulo: Martins Fontes, 2010. A coragem da verdade. São Paulo: Martins Fontes, 2012.

Freitas, A. S. A parresía pedagógica de Foucault e o êthos da educação como psicagogia. Revista Brasileira de Educação, Rio de Janeiro: ANPEd; Campinas: Autores Associados, v. 18, n. 53, p. 325-338, abr./jun. 2013.

Groppa,J. A. A difusão do pensamento de Michel Foucault na educação brasileira: um itinerário bibliográfico. Revista Brasileira de Educação, Rio de Janeiro: ANPEd; Campinas: Autores Associados, v. 18, n. 53, p. 301-324, abr./jun. 2013. 
Lopes, M. C.; Rech, T. L. Inclusão, biopolítica e educação. Educaşão, Porto Alegre: PUC-RS, v. 36, n. 2, p. 210-219, maio 2013.

Malabou, C. Ontologie de l'accident. Essai sur la platicité destructice. Paris: Éditions Léo Scheer, 2009.

PAGni, P. A. Infância, arte de governo pedagógica e cuidado de si. Educação छ Realidade, Porto Alegre: UFRGS, v. 35, n. 3, p. 99-123, 2010.

A pesquisa e o ensino no campo da filosofia da educação: críticas e possibilidades. In: Guedes, N. C.; Araujo, H. M.; Ibiapina, I. M. L. M. (Orgs.). Pesquisa em educą̧ão: contribuições ao debate na formação docente. Teresina: EDUFPI, 2013.v. 1, p. 111-146.

Filosofia da educação no Brasil: concepções, impasses e desafios para a sua constituição como campo de pesquisa e o seu ensino nas duas últimas décadas. Educação e Filosofia, Uberlândia: UFU, v. 28, n. 56, p. 773-808, jul./dez. 2014a.

. Experiência estética, formação humana e arte de viver: desafios à educação escolar. São Paulo: Edições Loyola, 2014a.

Rabinow, P.; Rose, N. O conceito de biopoder hoje. Politica E̊ Trabalho, João Pessoa: UFPB, n. 24, p. 27-57, 2006.

Revel, J. O pensamento vertical. Uma ética da problematização. In: Gros, F. (Org.). Foucault. a coragem da verdade. São Paulo: Parábola, 2004. p. 65-87.

Santos, I. M.; Klauss, V. A inclusão e o sujeito empresário de si. In: Fabris, E. H.; KLeIn, R. Inclusão e biopolítica. Belo Horizonte: Autêntica, 2013. p. 61-78.

SkLiar, C. Seis perguntas sobre a questão da inclusão ou de como acabar de uma vez por todas com as velhas - e novas - fronteiras em educação: educação especial e políticas inclusivas. Pro-Posiçôes, Campinas: UNICAMP, v. 12, n. 2-3, p. 11-21, 2001.

Veiga-Neto, A.; Lopes, M. C. Inclusão e governamentalidade. Educação E̋ Sociedade, Campinas: CEDES, v. 28, n. 100, p. 947-963, out. 2007.

Ugarte Pérez, J. Biopolítica: un análisis de la cuestión. Claves de Razón Práctica, Madrid: Progresa, n. 166, p. 76-82, oct. 2006.

\section{SOBRE O AUTOR}

Pedro Angelo Pagni é doutor em educação pela Universidade Estadual Paulista (UNESP). Professor da mesma instituição. E-mail: pedropagni@gmail.com 